\title{
Influence of Rake Angles of Multi-Position Tool on Cutting Characteristics
}

\author{
Shao-Hsien Chen ${ }^{1, *}$ and Chi-Hsiang Pan ${ }^{2}$ \\ 1 The Graduate Institute of Precision Manufacturing, National Chin-Yi University of Technology, \\ Tai-Chung 406, Taiwan \\ 2 Department of Mechanical Engineering, National Chin-Yi University of Technology, \\ Tai-Chung 406, Taiwan; pancs@ncut.edu.tw \\ * Correspondence: e6036@ncut.edu.tw; Tel.: +88-642-392-4505
}

Received: 19 April 2018; Accepted: 28 May 2018; Published: 14 June 2018

\begin{abstract}
During current high-speed cutting processing, the requirements on the $\mathrm{CNC}$ machine tool, controller, and cutting technique has become higher and higher. This research focuses on cutting tools, when the rake angles of different tools cause the shearing cut to change, and when the cutting force and cutting resistance are changed accordingly. In general, the rake angle is smaller in rough machining and bigger in finish machining. Therefore, the size of the rake angle should be decided on by considering the workpiece, feed-rate, cutting depth, cutting speed, cutter life, etc. In this research, we make different changes to the rake angle of the milling cutter and do real cutting tests to discuss the impact that rake angle change has on its processing characteristics. During the cutting experiment, by setting different cutting parameters, this research aims to get cutting force data using the dynamometer and the signal interceptor, and to analyze the relevance of the cutting force change, abrasion of tool, surface roughness, and chip morphology of different rake angles. This will be done through observation when the rake angle is $0^{\circ}$, when the cutting force in the $\mathrm{X} / \mathrm{Y} / \mathrm{Z}$ direction is the smallest, when the depth of the cut is 0.1 to $0.3 \mathrm{~mm}$, and when the tangential shear cutting constant $K_{t s}$ is reduced by $50 \%$.
\end{abstract}

Keywords: cutting force; rake angle; adjustable holder

\section{Introduction}

By changing different rake angles of tools, Lin [1] verified that when the rake angle of tools is increased, the maximum equivalent stress, the unit cutting force, and the cuttings temperature will decrease. Huang [2] once discussed the milling force and the post-processing surface roughness of the medium carbon steel and the fast cutting steel during turning and milling, and the experiment results showed that, under the same conditions, the smaller the cutting force endured by the tool during the cutting, the better the machinability was for the workpiece material. Moreover, a larger helical angle of the cutting tools means a bigger cutting rake angle, and thus the surface abrasion between the cuttings and the tool will be reduced and the shearing strain will also be reduced. However, the effective shear angle will be increased, which reduces the cutting force gradually $[3,4]$ so as to improve the processing efficiency. Many domestic scholars have carried out research in the field of measuring cutting force.

This research will apply the same holder to adjust the rake angle of the tool, and the cutting force change will then be observed. Furthermore, the ploughing force and the size effect during machining will be discussed, and the shearing effect of the face will be analyzed.

Koenigsberger and Sabberwal [5] have reported the empirical equation related to tangential force:

$$
f_{t}=c_{t}\left(t_{c}\right) \times t_{x} \times \sin \theta=k_{t} \times t_{x} \times \sin \theta
$$


In the mode of radial force established by Tlusty and Macneil [6], $k_{r}$ is the fixed ratio of the radial force and tangential force, and their relationship is shown as below:

$$
f_{r}=k_{r} \times f_{t}
$$

where in $t_{c}$ is the average cutting thickness, $k_{t}$ is the tangential cutting pressure constant. If the above equation does not consider the size effect, the $k_{t}$ is the definite value during cutting. However, if it does consider the size effect, $k_{t}$ will change with the cutting angle and therefore, the material characteristics, cutting parameters, and other factors must be considered when establishing the cutting mode. However, most scholars regard $k_{t}$ as a definite value during their research of the cutting force mode.

\section{Experimental}

\subsection{Cutting Tool Design with Adjustable Angle}

This research adopts the adjustable holder as shown in Figure 1, which can be applied to study high-speed cutting on the fixed holder and blade. The rake angle of the tool is mainly adjusted, and different rake angles of the tools have obviously different cutting characteristics. The key components of the adjustable cutting tools include the holder body, the rotation mechanism components, the positioning components, the anchor screws to the rotation mechanism components, the disposable blade, the anchor screws to the blade, and other important components. The rotation mechanism components are mainly adjusted and are fixed at different processing feed-rate speeds with different materials, as shown in Figure 2. The tool rake angle $\alpha$ and tool clearance angle $\eta$ will have different changes when adjusting the rotation mechanism components. The right side shows the side view, and the left side shows the front view-as shown in Figure 3. In this research, the analysis and studies will be carried out from different perspectives.

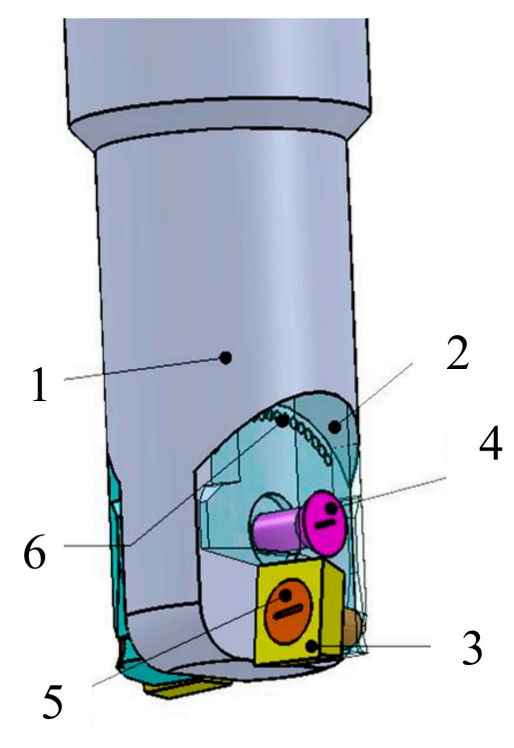

Figure 1. Adjustable holder design. 


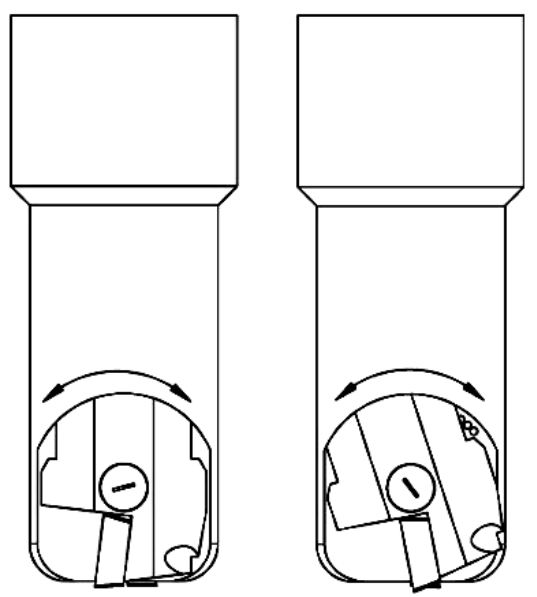

Figure 2. Mechanism to change the rake angle.

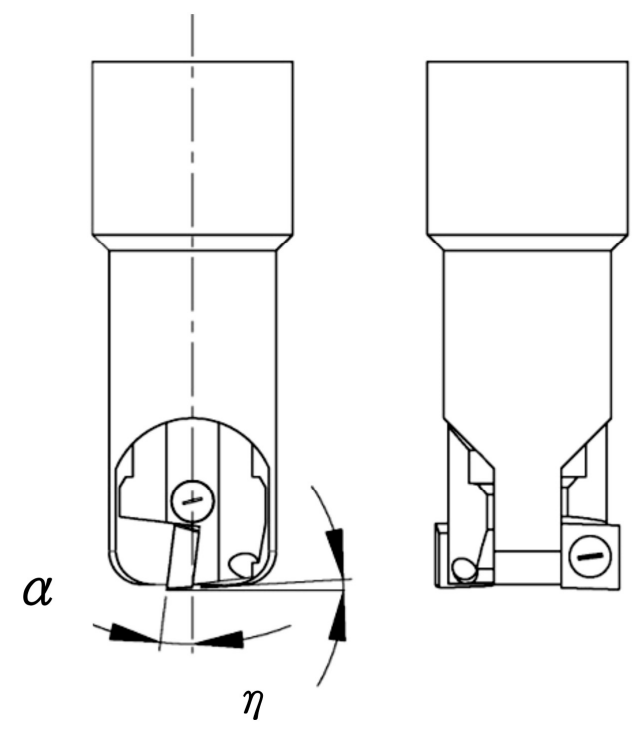

Figure 3. Impact of rake angle change on the rake angle and clearance angle.

In Figure $3, \alpha$ is the rake angle and $\eta$ is the clearance angle.

\subsection{Mathematical Model Derivation}

In general, cylindrical coordinate system $\rho-r-h$ changes with the rotation of the tool during milling, as shown in Figure 4. The angle $\rho$ is Zero when the height $(h)$ of one point at the edge of the milling cutter is zero $(h=0)$, and when the relationship of $\rho$ and $\mathrm{h}$ is as below [7-9]:

$$
\begin{gathered}
h(\rho)=\frac{R}{\tan \alpha}\left[\rho-(k-1) \rho_{a}\right] \\
(k-1) \rho_{p} \leq \rho \leq(k-1) \rho_{p}+\rho_{a}, k=1,2,3, \ldots, N
\end{gathered}
$$

$\rho_{p}$ is the included angle between the blades, while $\rho_{a}$ shows the relationship between the tool and its cutting height $d a$. However, the main effect variables of milling are the axial cutting depth $d a$, the radius of milling cutter $R$, the rake angle or helical angle $\alpha$ of the tool, and other parameters.

$$
\rho_{p}=\frac{2 \pi}{N}
$$




$$
\rho_{a}=\frac{d_{a}}{R} \tan \alpha
$$

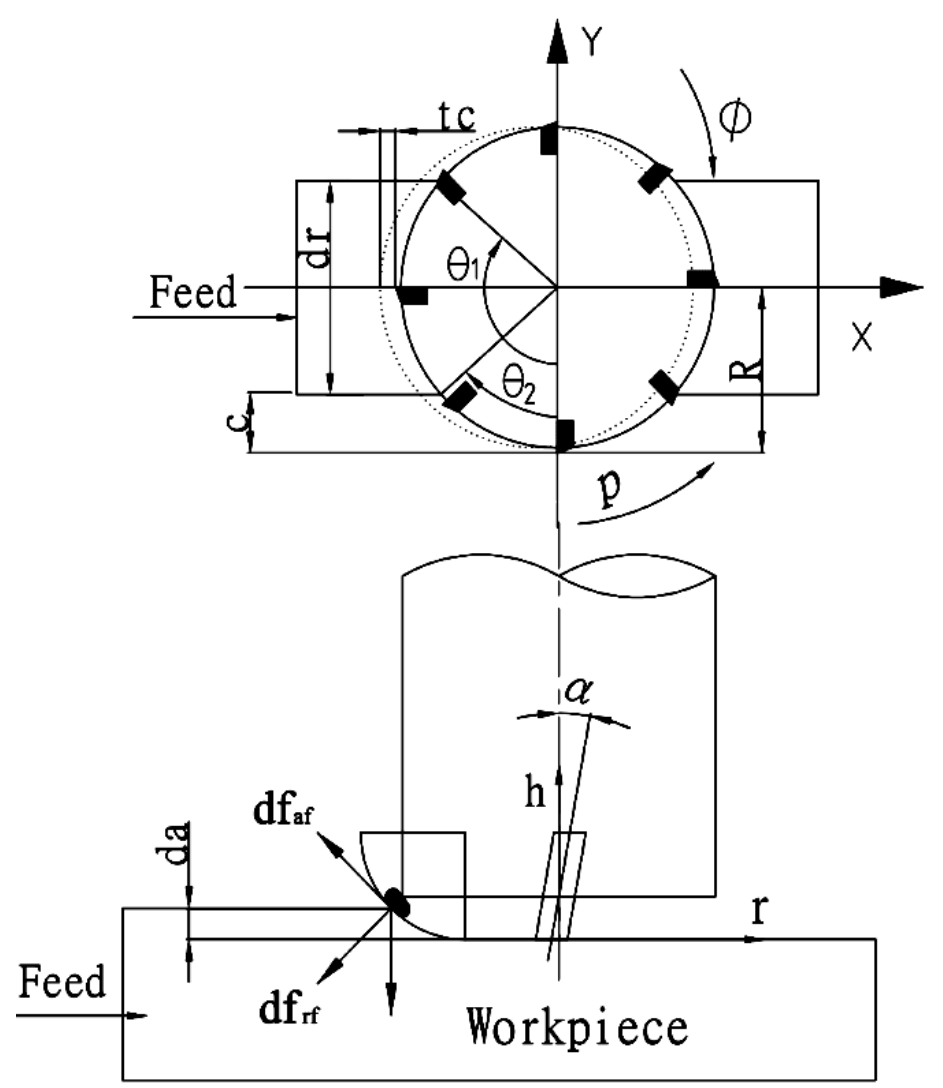

Figure 4. Milling cutter coordinate system.

When the rectangular coordinate system X-Y-Z is overlapped with the cylindrical milling cutter coordinate, the heading direction of the work-piece is the same as the $\mathrm{X}$-axis during the test. In addition, the $\theta$ angle is the cutting rotation angle between the tool and the work-piece during cutting, as shown in Figure 4.

$X-Y-Z$ coordinates are those for the work-piece during cutting when the milling cutter is fed along the $\mathrm{Z}$ axis, and when the rotation angle of the tool is $\theta$. The relationship between the milling cutter $\rho$ and the tool rotation angle $\phi$ can be shown on the work-piece coordinates as below.

During milling, the radial cutting-in $d r$ and the offset $C$ affect the relationship between the initial feed-rate angle $\theta_{1}$ and the final cutting angle $\theta_{2}$. The cutting thickness $t_{c}$ is a function of $\theta$, and the relation is as below:

$$
\begin{gathered}
\theta_{1}=\cos ^{-1}\left(\frac{R-C}{R}\right) \\
\theta_{2}=\cos ^{-1}\left(1-\frac{C+d r}{R}\right) \\
t_{c}=t_{x} \sin (\theta)
\end{gathered}
$$

During cutting, there is a contact point on the fillet of the cutting edge, as shown in Figure 5. The material above this point will be pushed to produce chips, and the material under this point will be pushed into the bottom of the tool. Then, the work-piece surface will be formed after the flank leaves. The position of the contact point will change with the geometrical shape and material of the tool, the material of the work-piece, and the cutting parameters [3]. The cutting force $F$ is divided into ploughing force $F_{P}$ and shear force $F_{S}$. 

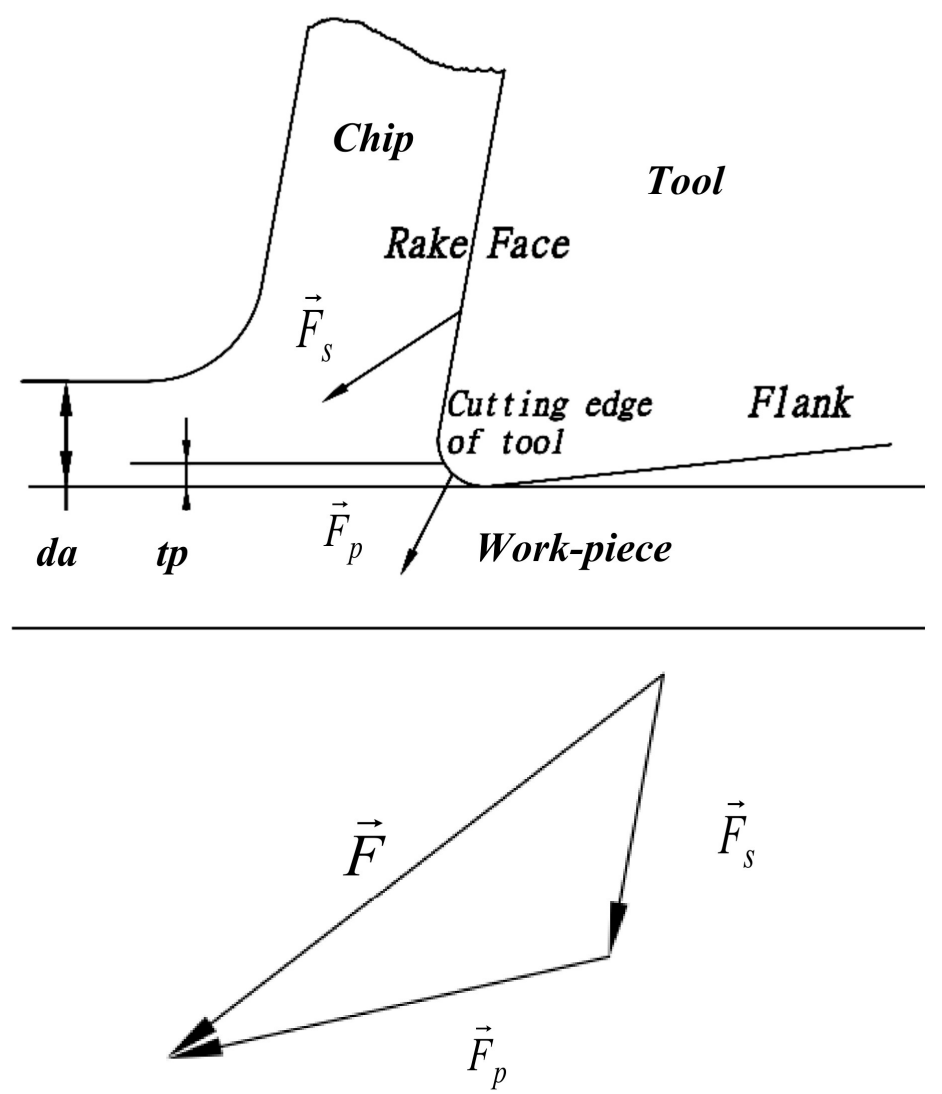

Figure 5. Diagram of shear force and ploughing force.

The impact of shear force and ploughing force on milling force can be divided into tangential, radial, and axial partial milling force, and the expression is shown in the below Equations (17)-(19).

The tangential, radial, and axial partial milling forces are shown in the following equation:

$$
\begin{gathered}
d f_{t}=k_{t s} t_{x} \sin \theta d h+k_{t p} d h \\
d f_{r}=k_{r s} k_{t s} t_{x} \sin \theta d h+k_{r p} k_{t p} d h \\
d f_{a}=k_{a s} k_{t s} t_{x} \sin \theta d h+k_{a p} k_{t p} d h
\end{gathered}
$$

The partial cutting by sorting is shown as below:

$$
\left[\begin{array}{l}
d f_{t} \\
d f_{r} \\
d f_{a}
\end{array}\right]=\left[\begin{array}{l}
1 \\
k_{r s} \\
k_{a s}
\end{array}\right] k_{t s} t_{x} \sin \theta d h+\left[\begin{array}{c}
1 \\
k_{r p} \\
k_{a p}
\end{array}\right] k_{t p} d h
$$

The process of converting the tangential force, radial force, and axial force into the $\mathrm{X}-\mathrm{Y}-\mathrm{Z}$ coordinated system is as follows:

$$
\begin{gathered}
{\left[\begin{array}{l}
d f_{x} \\
d f_{y} \\
d f_{z}
\end{array}\right]=\left[\begin{array}{lll}
\cos \theta & \sin \theta & 0 \\
\sin \theta & -\cos \theta & 0 \\
0 & 0 & -1
\end{array}\right]\left[\begin{array}{l}
d f_{t} \\
d f_{r} \\
d f_{a}
\end{array}\right]} \\
=\left[\begin{array}{lll}
1 & k_{r s} & 0 \\
-k_{r s} & 1 & 0 \\
0 & 0 & k_{a s}
\end{array}\right] k_{t s} t_{x}\left[\begin{array}{lll}
\frac{\sin 2 \theta}{2} \\
\frac{1-\cos 2 \theta}{2} \\
\sin \theta
\end{array}\right] d h+\left[\begin{array}{lll}
1 & k_{r p} & 0 \\
-k_{r p} & 1 & 0 \\
0 & 0 & -k_{a p}
\end{array}\right] k_{t p}\left[\begin{array}{l}
\cos \theta \\
\sin \theta \\
1
\end{array}\right] d h
\end{gathered}
$$




$$
=q_{s} p_{s} d h+q_{p} p_{p} d h
$$

The $p_{s}(\theta), p_{p}(\theta)$ is limited by the initial cutting angle $\theta_{1}$ and the final cutting angle $\theta_{2}$ during machining. Therefore, the basic cutting function must be multiplied with a cutting window function $\mathrm{W}$ $(\theta, h)$. During cutting, $\theta$ will be changed by the height of milling $h$ and the partial milling force mode when considering the cutting window is as follows:

$$
w(\theta)= \begin{cases}1 & \text { when.. } \theta \in\left[\theta_{1}, \theta_{2}\right] \\ 0 & \text { otherwise }\end{cases}
$$

The single blade cutting mode is obtained from the integration of the partial milling force function and the cutting height, which can be shown as follows:

$$
\begin{gathered}
f_{j}(\varphi)=\int d f=\int_{0}^{d a}\left\langle\left[q_{s}\right]\left[p_{s}\right]+\left[q_{p}\right]\left[p_{p}\right]\right\rangle w(\theta) d h \\
t s(\phi)=\sum_{k=-\infty}^{\infty} \delta\left(\phi-(k-1) \beta_{p}\right) \\
f(\phi)=t s(\phi) * f_{j}(\phi)
\end{gathered}
$$

The * stands for the operational symbol of convolution. During single blade cutting, it can be the convolution of the partial milling force function. General tools can do multi-blade milling, and the tools continuously rotate to cause the periodic change of the milling force. The periodicity is $\beta_{p}=2 \pi / Z$, therefore the force that is measured during processing is a periodic cutting force. The single blade mode is extended to be multi-blade periodic cutting force, by calculating the convolution of the single blade cutting force and the blade sequence function $t s(\phi)$. The total cutting force mode is as follows:

The average milling force is the important reference data during milling. The functions of the Fourier transform can be obtained when calculating the average value of the periodic function:

$$
\begin{gathered}
F(\omega)=T S(\omega) F_{j}(\omega) \\
=N \sum_{k=-\infty}^{\infty} \delta(\omega-N k) F_{j}(\omega)
\end{gathered}
$$

The Fourier transform equation for the TS $(\omega)$ blade sequence function ts $(\phi)$ is:

$$
T S(\omega)=N \sum_{k=-\infty}^{\infty} \delta(\omega-N K)
$$

We make the Fourier transform based on the above equation. The total milling force function can be shown as the form of Fourier transform series:

$$
\begin{gathered}
f(\phi)=\frac{1}{2 \pi} \int_{-\infty}^{\infty} F(\omega) e^{j \omega \phi} d \omega=\sum_{k=-\infty}^{\infty} A[N k] e^{j N k \phi} \\
A[N k]=\frac{N}{2 \pi} Q_{s}(N k) P_{s}(N k)+\frac{N}{2 \pi} Q_{p}(N k) P_{p}(N k)
\end{gathered}
$$


The specific cutting force constant is the important parameter to calculate the cutting force. This can be used to calculate the six unknown specific cutting force constants $k_{t s}, k_{r s}, k_{a s}, k_{t p}, k_{r p}$, and $k_{a p}$ by adopting slot milling and semi-slot milling. The equation is as follows [9-11]:

$$
\left[\begin{array}{l}
k_{t s} t_{x} \\
k_{r s} k_{t s} t_{x} \\
k_{a s} k_{t s} t_{x} \\
k_{t p} \\
k_{r p} k_{t p} \\
k_{a p} k_{t p}
\end{array}\right]=\frac{2 \pi}{N R_{0}} T^{-1}\left[\begin{array}{l}
A_{x h s}[0] \\
A_{y h s}[0] \\
A_{z h s}[0] \\
A_{x s}[0] \\
A_{y s}[0] \\
A_{z s}[0]
\end{array}\right]
$$

Therefore, the integrated convolution cutting force mode of milling cutter's slot milling can be set up. The convolution cutting force mode includes tool geometry (radius, helical angle), cutting conditions (axial and radial cutting depth), material parameters (specific cutting force constant), and other important parameters in the milling process. These can be applied to imitate cutting under various milling conditions $[4,12,13]$.

\subsection{Equipment and Method}

Two different materials of medium carbon steel S45C are used in this cutting experiment. The cutting signal is read by a dynamometer and data capture box, and the cutting force data are then analyzed by software. Relevant comparisons are then made after these calculations. The cutting experiment and the measurement method are shown in Figure 6. Moreover, the chips of milling and the blades are sorted, and a picture is taken to observe the tool abrasion and chip change so as to explain the status and phenomenon of the experiment. The tested work-piece applies the surface rough-meter to measure the surface profile of each finished surface. The feed per tooth $(f t)$ has three feed per tooth of $0.1,0.2$, and 0.3 (mm/tooth). The cutting depth (ap) has three equal parameters of 0.1 , 0.2 , and $0.3 \mathrm{~mm}$. The specifications of the tools are shown in Table 1. Tool material of $\mathrm{H}$ type is then coated in material TiALN. Cutting condition in the spindle speed by corporation to the recommended value, when the used S45C material by the spindle rotation speed for $\mathrm{N}=2500 \mathrm{rpm}$, the experiment flow chart as shown in Figure $6 b$.

Table 1. Relative specifications of the tools and blade.

\begin{tabular}{ccccc}
\hline Specification of Holder & Item No. of Blade & Material of Tool & Tooth Qty & Company \\
\hline BXD4000R252SA25SA & XDGT1550PDER-G15 & Coated TiAlN & 2 & MITSUBISHI \\
\hline
\end{tabular}

Experiments using the machine tool is gantry-type for three-axis vertical machining centres. Spindle speed is $14,000 \mathrm{rpm}$ and the spindle taper is in the form of HSK-A80. The $\mathrm{X} / \mathrm{Y} / \mathrm{Z}$ axis has a rapid feed-rate of $20 \mathrm{~m} / \mathrm{min}$ and a working feed-rate of $8 \mathrm{~m} / \mathrm{min}$. 


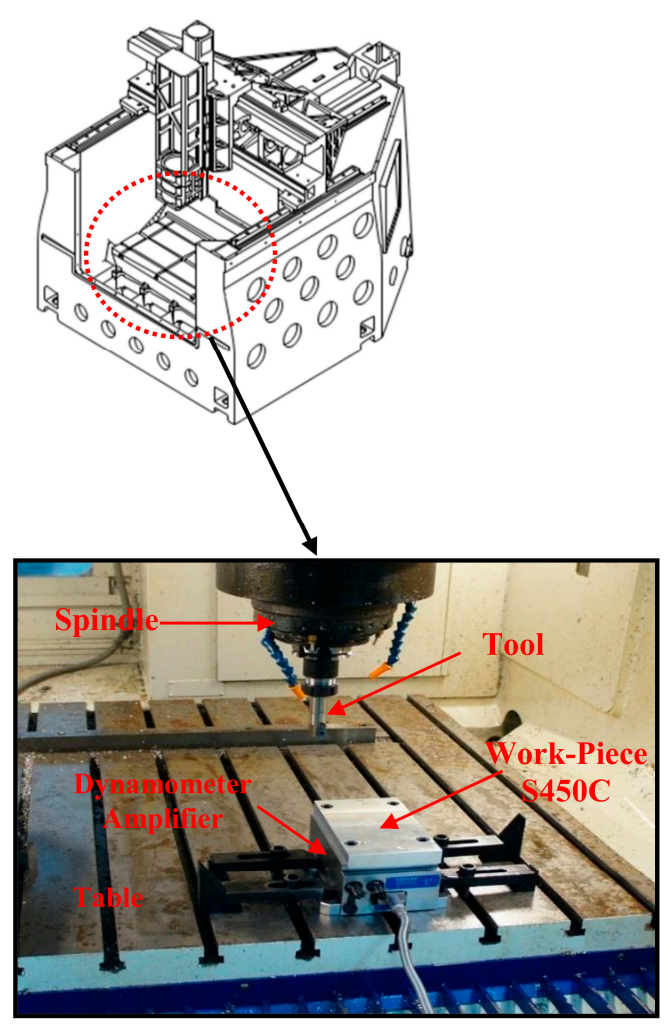

(a)

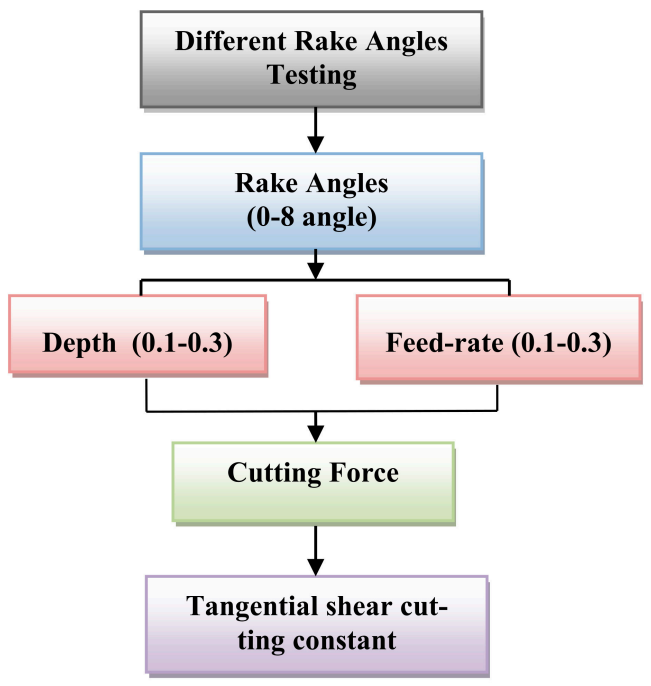

(b)

Figure 6. (a) Experiment equipment and method of measurement; (b) Experiment flow chart.

\section{Discussion}

\subsection{The Impact of Different Cutting Depths on Cutting Characteristics}

Different tool rake angles in cutting characteristics can obviously affect the cutting force. When the cutting rake angle and cutting depth is too big, the cutting force also increases relatively, as shown in Figure 7a-c. The main reason for this is that when the rake angle is big, the contact area of the flank is increased, which causes an increase of the cutting force. In this experiment, the direction of the $X$ axis is the feed-rate cutting direction, thereby the cutting force in the direction of the $X$ axis is 
big. With different cutting depths, the bigger the cutting depth is, the smaller the stress the $\mathrm{Z}$ axis is, which is mainly affected by the size effect. Therefore, the tangential shear effect and the tangential plough effect will be discussed.

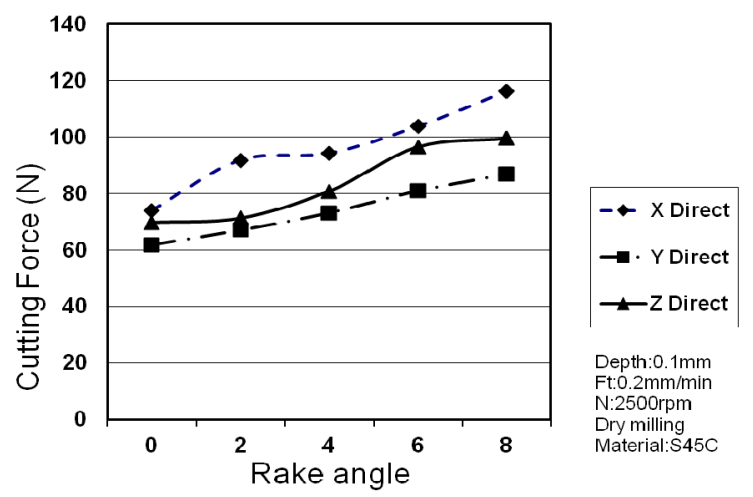

(a)

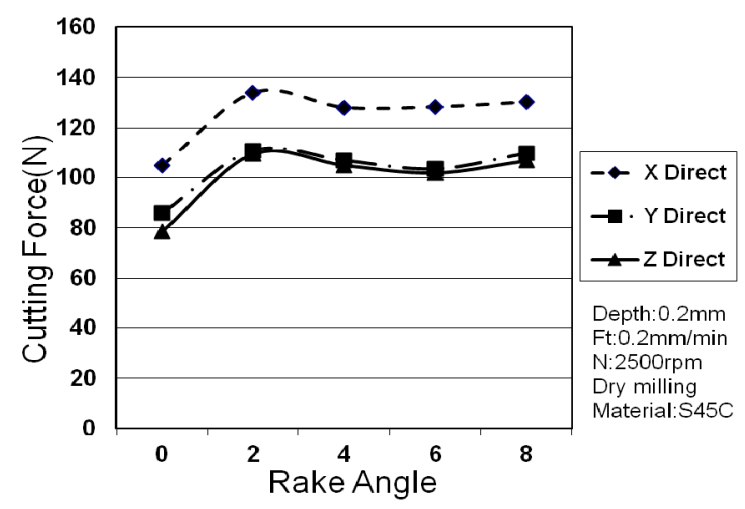

(b)

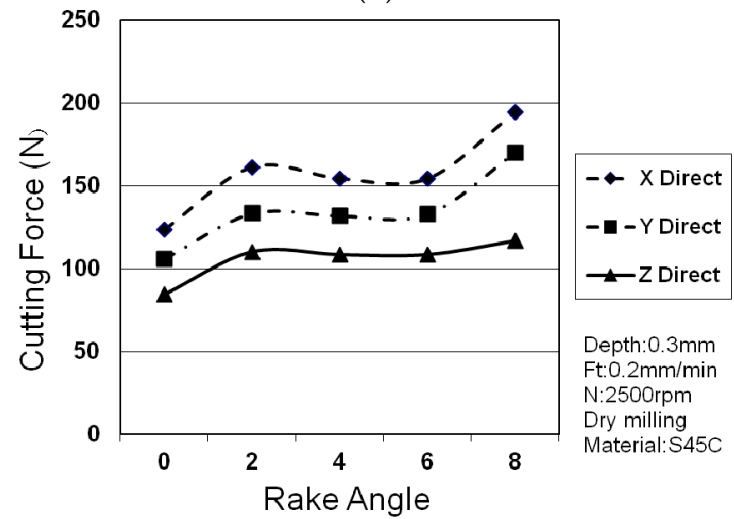

(c)

Figure 7. (a) The impact of different cutting depths of $0.1 \mathrm{~mm}$ on the cutting force; (b) The impact of different cutting depths of $0.2 \mathrm{~mm}$ on the cutting force; (c) The impact of different cutting depths of $0.3 \mathrm{~mm}$ on the cutting force.

Generally, $K_{t s}$ is the tangential shear constant, and its unit is MPa or N/mm². In the physical sense, it means the energy consumption when removing work-piece material per unit volume, in the unit of $\left(\mathrm{J} / \mathrm{mm}^{3}\right)$. It can be divided into shear effect and plough effect in general cutting. In shear effect, $K_{t s}$ is the cutting constant of tangential shear force, which can stand for the tangential cutting power of removing the non-deformable chip sectional area per unit, or the power of removing material per unit volume. This includes the chip deformation energy of the main shear area and the energy consumption caused by abrasion of the second shear area and tool rake angle. This parameter can be 
used to estimate the difficulty level of removing the material. In the plough effect, $K_{t s}$ is the cutting constant of the ploughing force, which can stand for the abrasion of the contact width between the unit tool and work-piece and the plough effect. Therefore, the cutting constant of the tangential plough force has much to do with the abrasion of the flank.

The cutting force constant will be increased as the cutting depth becomes smaller. This is mainly because of the size effect during cutting processing. Shaw [14] illustrates this with the dislocation theory, as a big shear force must be given to the cutting material with a small shear area to cause plastic deformation. Figure 8 shows that the smaller the feed per tooth $t c$ is, the bigger the tangential shear cutting constant $K_{t s}$ is. As shown in Figure 8, the smaller the cutting chip thickness is, the bigger the driving force that is needed in processing [15]. Correspondingly, the shear cutting constant is bigger, and the average cutting force is also obviously improved. The precipitation of material by hardening, and the size effect are main reasons for this [16-22].

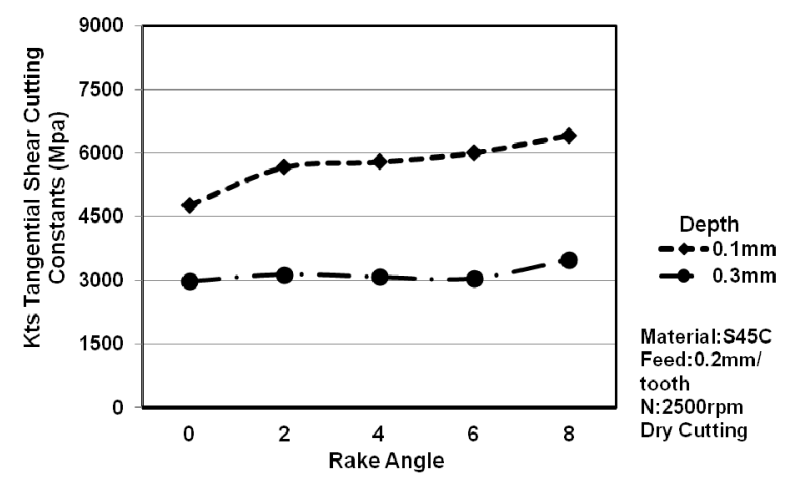

Figure 8. The impact of different cutting depths on the tangential shear constant.

The ploughing force mainly shows the relationship between the contact length of the flank and the work-piece [8], as shown in Figure 9. When the cutting rake angle is increased, the contact length of the flank and the work-piece is also increased, which causes the increase of the ploughing force. Thereby, the cutting rake angle increases relative to increases in the cutting force, which is mainly because the increase in the contact length of the flank and work-piece causes the increase of the tangential plough constant. Therefore, the tool clearance angle will be increased relatively when the cutting rake angle increases.

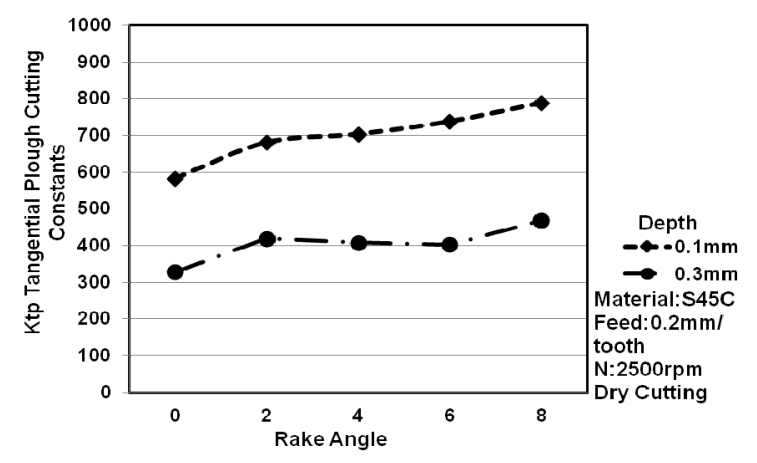

Figure 9. Impact of different cutting depths on the tangential plough constant.

\subsection{The Impact of Different Feed-Rates on Cutting Characteristics}

When the rake angle of the tool is changed at the same cutting depth, when the rake angle of the tool increases, the cutting force also increases (shown in Figure 10a,b). The main reason for this is the increase of the contact length of the flank. When the cutting feed-rate is increased, the cutting force gradually approaches to stability. Therefore, high-speed cutting is better for cutting processing. 


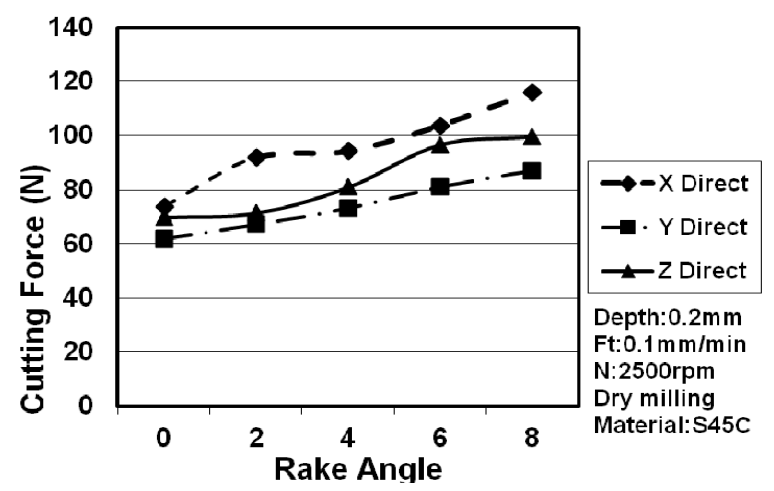

(a)

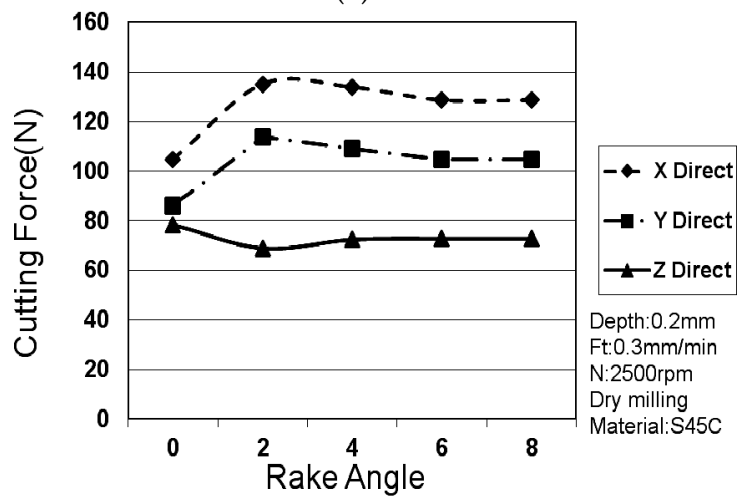

(b)

Figure 10. (a) The impact of the different feed-rate of $0.1 \mathrm{~mm} / \mathrm{min}$ on cutting force; (b) The impact of different feed-rates of $0.3 \mathrm{~mm} / \mathrm{min}$ on cutting force.

When the cutting depth is a definite value, we observed a relationship between the tangential shear constant and the cutting rake angle, as shown in Figure 11. The feed-rate per tooth of $F_{t}=0.3 \mathrm{~mm} /$ tooth is bigger than $F_{t}=0.1 \mathrm{~mm} /$ tooth in the tangential shear constant. Therefore, the impact of the feed-rate per tooth and the tool rake angle on the tangential shear constant is non-significant.

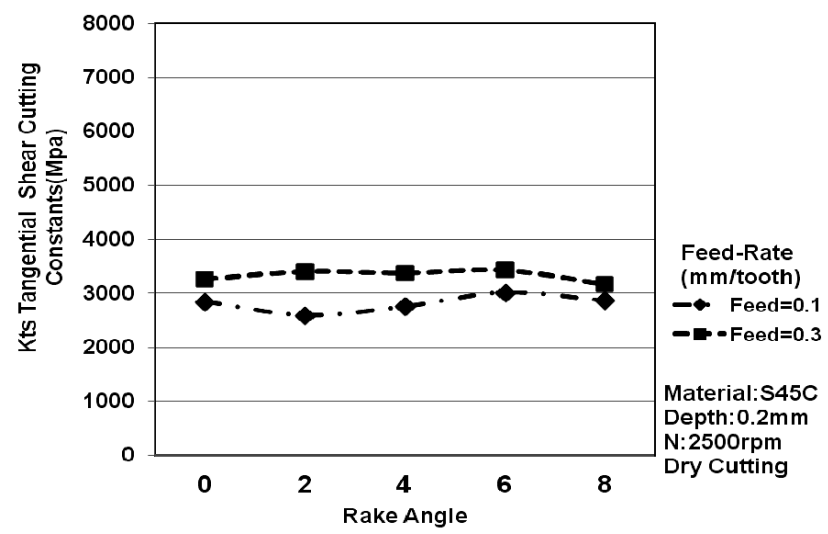

Figure 11. The impact of the different feed-rate per tooth on the tangential shear constant.

The feed-rate per tooth of $F_{t}=0.3 \mathrm{~mm} /$ tooth is bigger than $F_{t}=0.1 \mathrm{~mm} /$ tooth in the tangential plough constant. The main reason for this is that $F_{t}=0.3 \mathrm{~mm} /$ tooth of the feed system is big, the contact distance with the flank is long, and thereby the tangential plough constant is big (as shown in Figure 12). 


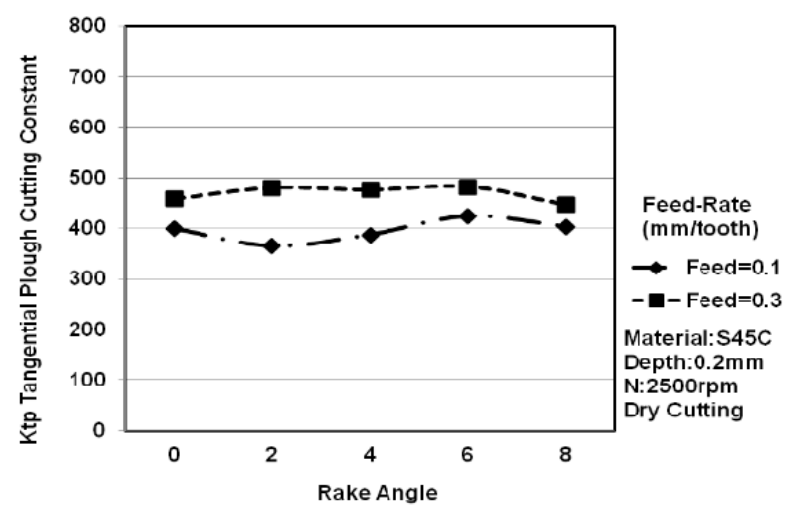

Figure 12. The impact of the different feed-rate per tooth on the tangential plough constant.

\section{Conclusions}

- In order to avoid increasing the tangential plough constant and the tangential shear constant of tools, which might increase the cutting force and further reduce the service life of tools, the clearance angle of the tools should be increased. This is because, as the cutting rake angle increases, when the rake angle is $0^{\circ}$, the cutting force in the $X / Y / Z$ direction is the smallest.

- The smaller the cutting depth is, the bigger the tangential plough constant and the tangential shear constant are. The main reason for this is that the size effect causes the bigger tangential shear constant, and the contact length of the flank is the primary cause for the big tangential plough constant.

- When the cutting feed-rate is changed, the bigger the feed-rate is, the bigger the tangential plough constant and the tangential shear constant are. The main reason for this is that the removal rate per unit of time is big, however the effect is not too big and the impact on the different rake angle of tools is not obvious.

Author Contributions: C.-H.P. design and analysis of tool handles; S.-H.C. machine test and analysis.

Funding: This research received no external funding.

Acknowledgments: This research received no external funding

Conflicts of Interest: The authors declare no conflict of interest.

\section{References}

1. Lin, Y.M.; Tai, C.C. A Coupled Thermal and Mechanical Finite Element Model of Orthogonal Metal Cutting with Deformable Cutting Tools. Master's Thesis, Tatung University, Taipei, Taiwan, 2009.

2. Huang, T.H. Study of Evaluation Criteria for Machinability of Steel; NCKU: Taipei, Taiwan, 2002.

3. Dewes, R.C.; Aspinwall, D.K. A review of ultru high speed milling of hardened steels. J. Mater. Process. Technol. 1997, 69, 1-17. [CrossRef]

4. Karandikar, J.; Mcleay, T.; Turner, S.; Schmitz, T. Tool wear monitoring using naive Bayes classifiers. Int. J. Adv. Manuf. Technol. 2014, 75, 5-8. [CrossRef]

5. Koenigsberger, F.; Sabberwal, A.J.P. An investigation into the cutting force pulsations during milling operations. Int. J. Mach. Tool Des. Res. 1961, 1, 15-33. [CrossRef]

6. Tlusty, J.; Macneil, P. Dynamics of cutting forces in end milling. CIRP Ann. 1975, 24, 21-25.

7. Wang, J.J.; Zheng, C.M. On-line identification of shearing and plowing constants in end milling. ASME J. Manuf. Sci. Eng. 2003, 125, 58-65.

8. Wang, J.J.; Zheng, C.M. An analytical force model with shearing and ploughing mechanisms for end milling. Int. J. Mach. Tools Manuf. 2002, 42, 761-771. [CrossRef]

9. Wang, J.J.; Huang, C.Y. Analysis of Process Damping and System Dynamics in Milling; NCKU: Taipei City, Taiwan, 2006. 
10. Martellotti, M.E. An analysis of the milling process. Trans. ASME 1941, 63, 677-700.

11. Engin, S.; Altintas, Y. Mechanics and dynamics of general milling cutters. Part I: Helical end mills. Int. J. Mach. Tools Manuf. 2001, 41, 2195-2212. [CrossRef]

12. Ozel, T.; Altan, T. Process simulation using finite element method-prediction of cutting forces, tool stresses and temperatures in high—Speed flat end milling. Int. J. Mach. Tools Manuf. 2000, 40, 713-738. [CrossRef]

13. Smith, S.; Tlusty, J. An overview of modeling and simulation of the milling process. J. Eng. Ind. 1991, 113, 169-175. [CrossRef]

14. Shaw, M.C. Metal Cutting Principle; Clarendon Press: New York, NY, USA, 1984; Chapter 14.

15. Wang, J.J.; Liang, S.Y.; Book, W.J. Convolution analysis of milling force pulsation. ASME J. Eng. Ind. 1994, 116, 17-25. [CrossRef]

16. Zheng, L.; Li, Y.; Liang, S.Y. A generalized model of milling forces. Int. J. Adv. Manuf. Technol. 1998, 14, 160-171. [CrossRef]

17. Kline, W.A.; DeVor, R.E.; Snareef, I.A. The prediction of surface accuracy in end milling. J. Eng. Ind. 1982, 104, 272-278. [CrossRef]

18. Schulz, H.; Moriwaki, T. High-speed machining. Ann. CIRP 1992, 41, 637-643. [CrossRef]

19. Karandikar, J.; Schmitz, T.; Abbas, A. spindle speed selection for tool life testing using Bayesian inference. J. Manuf. Syst. 2012, 31, 403-411. [CrossRef]

20. Otto, A.; Radons, G. The influence of tangential and tensional vibrations on the stability lobes in metal cutting. Nonlinear Dyn. 2015, 82, 1989-2000. [CrossRef]

21. Ganesh babu, B.; Selladurai, V.; Shanmugam, R. Analytical modeling of cutting forces of end milling operation on aluminum silicon carbide particulate metal matrix composite material using response surface methodology. J. Eng. Appl. Sci. 2008, 3, 195-196.

22. Wyen, C.-F.; Jaeger, D.; Wegener, K. Influence of cutting edge radius on surface integrity and burr formation in milling titanium. Int. J. Adv. Manuf. Technol. 2013, 67, 589-599. [CrossRef]

(C) 2018 by the authors. Licensee MDPI, Basel, Switzerland. This article is an open access article distributed under the terms and conditions of the Creative Commons Attribution (CC BY) license (http:/ / creativecommons.org/licenses/by/4.0/). 